\title{
"Green neology" and its role in environmental education (a media discourse approach)
}

\author{
Alla Guslyakova ${ }^{*}$, Nailya Valeeva ${ }^{2}$, Olga Vatkova ${ }^{3}$ \\ ${ }^{1}$ Peoples' Friendship University of Russia (RUDN University), Faculty of Ecology, 6 Miklukho- \\ Maklaya St, Moscow, 117198, Russian Federation; Moscow Pedagogical State University, Institute of \\ Foreign Languages, Moscow, Russia \\ ${ }^{2}$ Peoples' Friendship University of Russia (RUDN University), Faculty of Ecology, 6 Miklukho- \\ Maklaya St, Moscow, 117198, Russian Federation \\ ${ }^{3}$ Secondary school "Cvetan Spasov", Pleven, Bulgaria
}

\begin{abstract}
The article covers the problem of ecological neologisms which mostly appear in the present-day media discourse space and actively function there by making a significant impact on people's environmental worldview. Moreover, the research also raises the problem of neologisms as an effective educational instrument for raising human ecological awareness. A comparative analysis of the most popular neologisms circulated in the Russian, British and American media discourse space is introduced in the study. Finally, it is suggested that green neology in its close correlation with media ecology provide a foundation for building and developing a new ecosystemic society with more sustainable ideology towards the future of the planet.
\end{abstract}

\section{Introduction}

Language of human beings has the design feature of creativity due to its duality, and the feature of duality of structure of the language system is a crucial feature of human language [1]. Modern linguistics considers the language to be a complex dynamic system, the direction and nature of the evolution of which are subject to the general laws of dialectics.

The most active development of the language is regarded in the field of vocabulary. This can be explained due to a number of its features in comparison with other language levels and, in particular, a higher degree of extra-linguistic determination [2]. The concept of extralinguistic determination is closely related to another important notion introduced by Edward Sapir - "the drift of a language", which can be characterized as "constituted by the unconscious selection on the part of its speakers of those individual variations that are cumulative in some special direction" [3]. Since the phenomenon of the present-day world are divided into products of nature, products of culture as well as the products of massive digital technologies, there is certainly a need for linguistic and learning (educational) action when newly developed objects or new concepts have to be named.

\footnotetext{
* Corresponding author: guslyakova_av@pfur.ru
} 
At the turn of the $\mathrm{XX}^{\text {th }}$ and the $\mathrm{XXI}^{\text {st }}$ centuries humankind faced severely the problem of environmental pollution and a negative human impact on the natural resources of the planet because of the increasing role of scientific and technological revolution. To a varying degree, all natural components of the environment have undergone a change. Therefore, people started actively protesting against the destruction of Nature trying to stop its barbarian exploitation. As a result, a lot of new ecological words and concepts (neologisms) appeared and continue appearing in the languages, for example: eco-conscious, eco-speak, ecotourism, eco-refugee, etc. Moreover, today, the words "ecology", "environment", "sustainability" have become one of the most widely circulated terms which are used not only by scientists, but also by economists, politicians, journalists and specialists from many branches of industrial and social spheres of human activity. All these important ecological neologisms are actively introduced in the media discourse environment and used in the written and oral speech by people in different languages and countries. Thus, the purpose of this research is to show how ecological neologisms created and popularized through the media discourse space may change people's environmental behavior and make them become more eco-friendly while keeping a more sustainable lifestyle.

\section{Objects and Methods.}

\subsection{Neology as an important branch of modern linguistics and social sciences}

In connection with the orientation of modern linguistics to the study of the processes of language development, a deep and comprehensive study of neologisms and neology are of undoubted interest. The term "neology" (from French "néologie") first appeared in France in 1758 and obtained its linguistic meaning by the end of the XIX ${ }^{\text {th }}$ century. Today neology has become a special branch of linguistics that studies the most dynamic language layer - the vocabulary - and focuses on neologism which is described as "a new word or a new meaning for an established word; the use of, or the practice of creating, new words or new meanings for established words" [4]. Neologisms must be understood as words that appeared at a certain period in the language, "arising from the memory of the generation that uses them" [5]. That is, neologisms possess relative and historical properties [6].

Neologisms, arising in discourse, can turn into linguistic units or remain individual entities. They are quite often spread and popularized in the media discourse space. Newspapers, magazines, video channels, social networks have become centres of attraction for neologisms which are popular vocabulary units among different categories of media users.

Thus, neologisms are created to be used by people, which is the pragmatic aspect of neology, but the leading role in the birth of neologism remains due to the cognitive aspect and it is necessary to determine the place of a new word in the speaker's mind as well as relate it to a certain category [7]. It is essential to mention that in the recent decade a significant part of neologisms are lexical units related to the field of ecology. Some of them have become ecological terms, which get fixed in the language because of the viability of the objects of reality they denote.

\subsection{Environmental neologisms and sustainable development through a media discourse perspective}

At present, the media discourse space occupies a significant part of human life. Media discourse reflects the recent state of society, the latest trends and important actual problems in the world, including environmental issues. New values and social functions of media may 
turn out as the most fundamental question concerning the new media environment [8]. Accordingly, one of the most important questions of the media discourse speculation turns out to be about the role of digitalization of the media means for society as a whole. How is the change in the media related to the general change in society, including its sustainable development?

In the present-day media research, such comprehensive social questions are studied especially within the media ecology research tradition. Media ecology sees the media discourse not only as means of communication, but more as social environments which are undergoing significant social changes. People are constructing a new social and cultural world which should become better, greener and more sustainable. Thus, a new "ecosystemic society" model is being built $[9,10]$ which is actively covered in the mass media environmental discourse.

This type of discourse includes speech genres such as brief informational notes, thematic articles, comments, reporting from the scene, interviews, essays, feuilletons, appeals, speeches, posters and slogans. The expressiveness of the language of the media environmental discourse allows its creators to influence people that belong to different social groups. This media influence is represented in instilling the audience certain ideas (for example, clothes production from recycled plastic), contributing to the emergence of not only an emotional reaction in the form of an experienced attitude, but also reactions in the form of physical actions (school climate strikes across the world inspired by an Swedish activist Greta Thunberg).

Therefore, the informative content of the media discourse is presented in oral and written texts which include key environmental concepts embodied in words that quite often become "green" neologisms. The use of neologisms fill the media discourse with bright speech shades and help its creators portray events more vividly and emotionally, express their thoughts and feelings clearly as well as play an important role in people's ecological literacy and education. Everyone knows that words are singularly the most powerful force available to humanity. Thus, ecological neologisms definitely have the power and ability to help, to heal, to inspire and to teach.

\section{3 "In words we trust" - the effect of green neologisms on environmental education}

Since people took an active interest in the environment and sustainable development in the 20th century, environmental terminology and ecological neologisms mainly consists of concepts that have appeared in the language relatively recently. At the turn of the $\mathrm{XX}^{\text {th }}-$ $\mathrm{XXI}^{\text {st }}$ centuries, social and political movements that advocate for the protection of the environment become extremely popular. As a result, there appeared terms denoting these movements.

For example, in the semantic structure of the word "green" another lexical and semantic variant appeared: 1) related to the protection of the environment; 2) a representative of the party of environmentalists. A similar process affected the semantics of the word "garbage", which also means "something perceived as worthless." Such semantic changes caused the emergence of a whole class of two-component neologisms, which are based on the transfer of value from a property to a subject. An example is the metonymic transfer of a characteristic to an object in this case: a green - a person associated with the protection of the environment. There have also been the formation cases of new stable combinations formed in this way: green consumers - people who buy only those products that are environmentally friendly; the green revolution - increased crop yields worldwide; green party - a formally organized political party based on the principles of green politics, such as social justice, 
environmentalism and nonviolence; green politics - environmental policy. In the above phrases, the meaning of the first element clarifies the meaning of the whole phrase.

Thus, the green component prescribes the phrase "related to environmental protection". A group of morphological neologisms with the prefix eco-, which is the meaning-forming centre, is formed in a similar way: eco-friendly - environmentally friendly, eco-freak - a supporter of environmental conservation, ecoterrorism - environmental terrorism, ecotourism - ecological tourism, ecowarriors - activists that disrupt commercial activities that may threaten the environment.

In the process of communication, a person needs a new word that expresses his communicative intention at the time of speech. As a result, such "green" neologisms appear as ecotage (ecology + sabotage) - sabotage organized for environmental reasons; environmentalism - a direction in science that promotes environmental protection; monkeywrencher - a fanatical environmentalist.

To sum up, we assume that while countless ecological neologisms can spark the interests of language learners (and teachers), one of the most critical issues affecting people globally remains the environmental degradation of the planet. Themes such as global warming, deforestation, and water pollution are regularly featured in the media discourse, thereby raising a person's awareness of the troubled state of the Earth. When educational institutions - from elementary schools to universities - recognize the value of environmental education, language teachers will be in a unique position to promote environmental awareness while teaching a mother language as well as a foreign one.

Many of today's educators understand the importance of protecting our planet and raising students' awareness and perception of the sustainable future. And thus in our research we are stating an example of how ecological neologisms basically circulated in the media discourse space may promote eco-friendly philosophy in students' consciousness and teach them to "become informed about as many issues as possible that intrinsically affect their lives" [11].

\subsection{Methods}

Synthesis of interpretive and comparative approaches applied to the studied material allows making use of a complex of methods, with the hypothetic and deductive method, analysis, statistical data processing, analogy and generalization, being the leading ones.

\section{Results}

As we have already mentioned above, neologisms are those words that have appeared in the language relatively recently. At present, there are a huge number of them, but for our research we selected 50 of the most interesting English-language and 45 Russian environmental neologisms. A statistical analysis of the selected neologisms was conducted in the Englishlanguage and Russian media discourse. For that purpose, we made a request for each neologism in the Google search engine. We will consider the process of collecting statistics on the example of the English ecological neologism garbology. As we can see in Fig. 1 the result was 97400 documents containing the neologism under discussion.

Garbology is the study of a person or group of people by examining what they throw away. "In Garbology, everyday pieces of trash suddenly become valuable and interesting artefacts from which many inferences about their source can be drawn" [12]. Garbology involves the careful observation and study of the waste products produced by a population in order to learn about that population's activities, mainly in areas such as waste disposal and food consumption. Garbage anthropologists, known as garbologists, can use rubbish to draw comparisons between what is known as real behaviour (what people actually do) and ideal behaviour (what people say they do or what they'd like to think they do). 


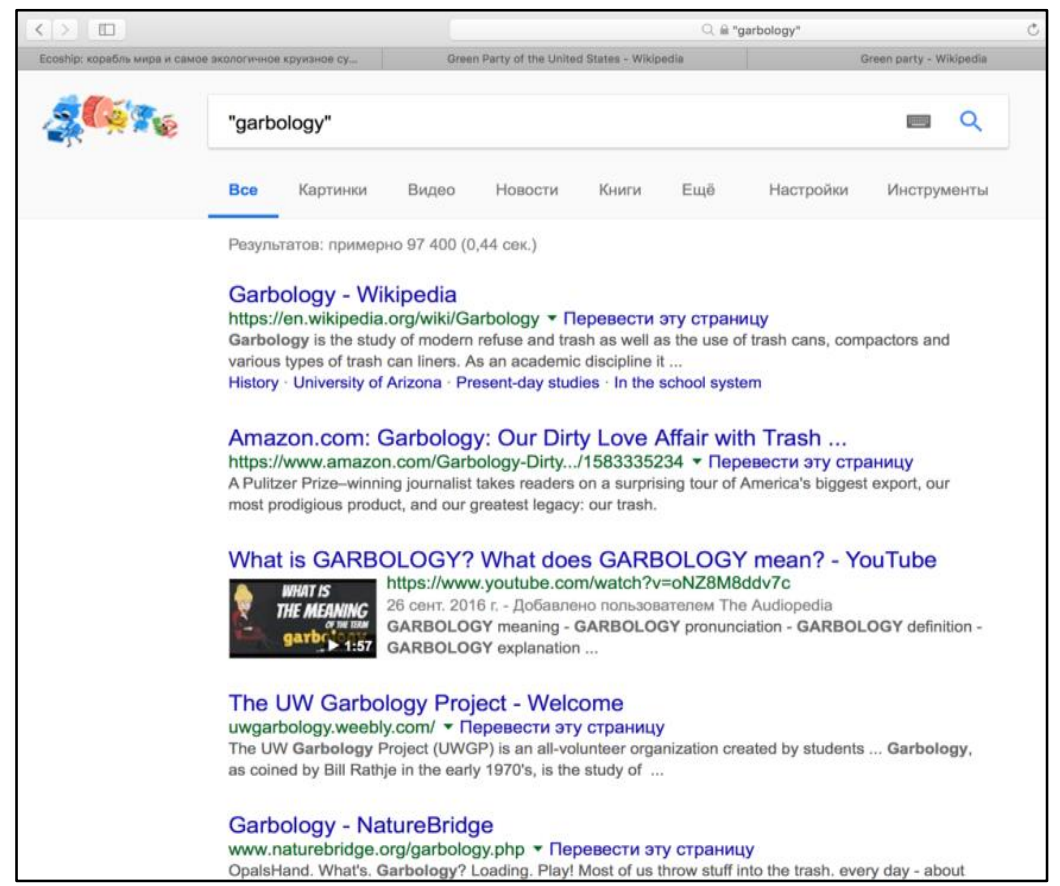

Fig. 1.The example of the request for the neologism "garbology" in Google search engine

This neologism has become very popular in the English and Russian media discourse space. Hence, we may observe how both Russian and English-speaking media are promoting garbology as a valuable method of young generation's upbringing as well as an effective way of training people to sort out their household waste.

For example,

"Where there's muck there's lessons to be learned. So says Suffolk county council, which has advertised for a garbology officer to teach pupils the value of old rubbish" [13].

Garbologists initiate the most advanced projects in the field of waste management - from Garbage 101 children's kits that teach children to be responsible for their waste, to the largescale My Garbogy program, which polarizes the same qualities among the adult population of the planet. Garbologists daily save the Earth from the inglorious end under the mountains of human waste, and we owe it to them with such technological breakthroughs as "Energy from waste" [14].

It is important to mention that after being neologisms for a certain period of time the words "garbology" and "garbologist" have turned into ecological terms which are frequently used not only in the media discourse space but also in other types of discourse, including academic discourse at schools and higher education institutions.

In our research we also managed to analyze other popular "green" neologisms which have become the key concepts of the present-day digital epoch and are bringing an important environmental mission in the world (see tables1, 2 and 3).

Tables 1, 2 and 3 demonstrate the most popular neologisms which are circulated in the British, American and Russian media discourse space. These environmental concepts can be characterized as vital life issues and challenges that people have to tackle at the present moment. 
Table 1. Statistics of search results for English-language neologisms in the most popular newspapers in the UK (number of articles found)

\begin{tabular}{|c|l|c|c|c|c|}
\hline \multirow{2}{*}{ Nr. Neologism } & \multirow{2}{*}{ Nometion } & Title of the mass media edition & Total \\
\cline { 3 - 6 } & & The Sun & The Daily Mail & Metro & \\
\hline 1 & Veganism & 82 & 4937 & 718 & 5737 \\
\hline 2 & Eco-friendly & 521 & 4606 & 596 & 5723 \\
\hline 3 & Environmentally friendly & 283 & 2920 & 639 & 3842 \\
\hline 4 & Pescatarian (also Pescetarian) & 45 & 289 & 87 & 421 \\
\hline 5 & Ecotourism & 45 & 337 & 30 & 412 \\
\hline 6 & Garbage man & 5 & 352 & 16 & 373 \\
\hline 7 & Green revolution & 7 & 148 & 48 & 203 \\
\hline 8 & Freecycle & 44 & 83 & 36 & 163 \\
\hline 9 & Locavore & 0 & 11 & 3 & 14 \\
\hline 10 & Ecofeminism & 0 & 1 & 0 & 1 \\
\hline
\end{tabular}

Table 2. Statistics of search results for English-language neologisms in the most newspapers in the USA (number of articles found)

\begin{tabular}{|l|l|c|c|c|c|}
\hline \multirow{2}{*}{ Nr. } & \multirow{2}{*}{ Neologism } & \multicolumn{2}{|c|}{ Title of the mass media edition } & \multirow{2}{*}{ Total } \\
\cline { 3 - 5 } & & $\begin{array}{c}\text { The New York } \\
\text { Times }\end{array}$ & $\begin{array}{c}\text { USA } \\
\text { Today }\end{array}$ & $\begin{array}{c}\text { The Los Angeles } \\
\text { Times }\end{array}$ & \\
\hline 1 & $\begin{array}{l}\text { Environmentally } \\
\text { friendly }\end{array}$ & 2250 & 669 & 565 & 3484 \\
\hline 2 & Eco-friendly & 1344 & 766 & 1044 & 3154 \\
\hline 3 & Veganism & 290 & 242 & 2060 & 2592 \\
\hline 4 & $\begin{array}{l}\text { Green } \\
\text { revolution }\end{array}$ & 1280 & 28 & 82 & 1390 \\
\hline 5 & Ecotourism & 807 & 109 & 134 & 1050 \\
\hline 6 & Locavore & 581 & 69 & 54 & 704 \\
\hline 7 & Garbage man & 421 & 70 & 54 & 545 \\
\hline 8 & $\begin{array}{l}\text { Pescatarian (also } \\
\text { Pescetarian) }\end{array}$ & 90 & 23 & 24 & 137 \\
\hline 9 & Freecycle & 81 & 7 & 5 & 93 \\
\hline 10 & Ecofeminism & 8 & 0 & 0 & 8 \\
\hline
\end{tabular}

Table 3. Statistics of search results for English-language neologisms in the most popular newspapers in Russia (number of articles found)

\begin{tabular}{|c|l|c|c|c|c|c|}
\hline $\begin{array}{l}\text { N } \\
\text { r. }\end{array}$ & \multirow{2}{*}{ Neologism } & \multicolumn{4}{|c|}{ Title of the mass media edition } & \multirow{2}{*}{ Total } \\
\cline { 3 - 6 } & & Izvestiya & Kommersant & Vedomosti & $\begin{array}{c}\text { Komsomol'skaya } \\
\text { pravda }\end{array}$ & \\
\hline 1 & Elektromobil' & 216 & 33 & 3490 & 3680 & 7419 \\
\hline 2 & Elektrobus & 37 & 99 & 181 & 1170 & 1487 \\
\hline 3 & Biotoplivo & 93 & 7 & 262 & 138 & 500 \\
\hline 4 & Ekoturizm & 62 & 0 & 21 & 192 & 275 \\
\hline 5 & Zelenyy ofis & 10 & 0 & 11 & 147 & 168 \\
\hline 6 & $\begin{array}{l}\text { Zelenaya } \\
\text { energiya }\end{array}$ & 5 & 1 & 3 & 23 & 31 \\
\hline 7 & Ekootel' & 0 & 0 & 4 & 10 & 14 \\
\hline 8 & $\begin{array}{l}\text { Zelenaya } \\
\text { kompaniya }\end{array}$ & 0 & 0 & 1 & 1 & 1 \\
\hline 9 & Ekostil' & 0 & 0 & 0 & 12 & 12 \\
\hline 1 & Ekotovar & 0 & 0 & 0 & 7 & 0 \\
0 & & & & & & \\
\hline
\end{tabular}


Metaphorically speaking neologisms are often referred to as "barometers" of the changes that happen in the society and the shifts in popular social tendencies [15]. On the one hand, new words reflect public consciousness but on the other hand, they influence its development [16]. The words and word combinations introduced in the tables above demonstrate people's intentions to build a more sustainable world on the planet and teach future generations to save the life on the Earth by maintaining an eco-friendly lifestyle.

\section{Conclusion}

Neology is a science that is directly related to almost all areas of human activity. "Green" neology is an essential language sphere which introduces a lot of important new words and collocations that describe the present-day environmental concept of human life. Since we are living in the epoch of digitalization and cutting-edge media technologies, environmental studies are closely interrelated with the media discourse resources. This symbiosis even led to the foundation of a new scientific approach that is called media ecology and it discusses a possible future, in "which the network society is deepening to become an internet-based ecosystemic society" [17]. Probably, ecological neologisms that are so frequently used in the media discourse space play important functions in the development of modern ecosystemic society. Firstly, they introduce ecological problems and estimate a current environmental situation. Secondly, they may reflect the reasons that stand behind the present-day ecological problems. Thirdly, green neologisms can give a hint on environmental problem-solving issues. Finally, they can inspire people to behave in a more eco-friendly way. Multiple media resources that contain a lot of useful information with the above mentioned neologisms have become effective mediators in people's ecological education process.

In summary, we would like to remark that the issue of green neology and ecological neologisms is highly topical and important. It is necessary to keep studying neologisms that cover the problem of sustainable development ideology through the media environmental discourse perspective so as to better understand how language, media and environmental education may change the human consciousness and lay the foundations of a more sustainable future on the planet.

\section{References}

1. C. Linhua, An Introduction to Linguistics (Jilin: Jilin University Press, 2008)

2. L.B. Gaztalova, Neology as a science in a general paradigm of a modern language (based on the Russian and Ossetian languages) (Nalchik, 2005)

3. R. Fischer, Lexical Change in Present-day English: A Corpus-based Study of the Motivation, Institutionalization, and Productivity of Creative Neologisms (Tübingen, Narr, 1998).

4. L. Zhou, Sino-US Engl. Teach., 13, 4, 292-295 (2016)

5. M.A. Ryashchenko, Vest. Chelyab. gos. univer., 16 (345), 91, 121-123 (2014)

6. F. Saussure, Cours de linguistique générale (Payot, 1995)

7. V.I. Zabotkina, Cognitive and pragmatic approach to the study of English neology (Proceed. of a scient. confer., Moscow, MGLU, 2002)

8. I. Siles, P.J. Boczkowski, New Media Soc., 14(8), 1375-1394 (2012)

9. J. Ruotsalainen, S. Heinonen, Europ. Jour. of Fut. R., 3, 9 (2015)

10. M. Lister, J. Dovey, S. Giddings, I. Grant, K .Kelly, New media: a critical introduction (Routledge, London, 2003).

11. H.D. Brown, The Lang. Teach., 15 (8), 4-5 (1991). 
12. Buzzword

“Garbology".

URL:

https://www.macmillandictionary.com/buzzword/entries/garbology.html

13. K. Scott, The Guard. (2004).URL: https://www.theguardian.com/society/localgovt/news/0,8368,1349317,00.html

14. What is Garbology and why is it so important? URL: https://w2e.ru/blog/chto-takoegarbologiya-i-pochemu-ona-vazhna/

15. W. Croft, Social Evolution and Language Change (Manchester, University of Manchester, 2007)

16. N.L. Shamne, I.V. Rets, Vestn. Volgogr. gos. un-ta. Ser. 2, Yazykozn, 1 (25), 72-77 (2015)

17. J. Ruotsalainen, S. Heinonen, Europ. Jour. of Fut. R., 3, 9 (2015) 